\title{
Tetracycline and Acne Vulgaris: a Clinical and Laboratory Investigation
}

\author{
W. J. CUNLIFFE, \\ R. A. FORSTER, \\ N. D. GREENWOOD, C. HETHERINGTON, \\ K. T. HOLLAND, \\ R. L. HOLMES, \\ S. KHAN, \\ C. D. ROBE \\ C. HET
} B. WILLIAMSON

\section{Materials and Methods}

We investigated 13 patients aged 13 to 21 years (mean age $17 \cdot 2$ years +2.6 S.D.) with a moderate degree of acne. They received no oral or topical therapy for at least one month before treatment. After the initial investigations they were given oral tetracycline hydrochloride B.P. (Lederle Laboratories, Ltd.) $250 \mathrm{mg}$ a day and instructed to take one tablet half an hour before a light breakfast, continuing the treatment for three months.

Before and at each monthly visit we assessed and measured (1) the clinical state; (2) serum tetracycline level; (3) skin surface lipid composition; (4) keratin coating of the pilosebaceous duct; and (5) pilosebaceous bacteria. The serum tetracycline level was estimated in $1 \mathrm{ml}$ aliquots of serum by a modification of Kohn's (1961) fluorimetric technique. The surface lipid was collected by ether-soaked polyurethane sponge and the composition determined by thin-layer chromatographic methods by the technique of Cotterill et al. (1971 a). Pilosebaceous keratin was removed with a cyanoacrylate gel placed on the skin, the sample being examined by surface microscopy by the methods of Holmes et al. (1972). The number of hairs $/ \mathrm{cm}^{2}$ which were coated with pilosebaceous keratin were counted and the degree of coating was assessed by using an arbitrary scale (0-5).

The pilosebaceous duct bacteria were sampled by using a cyanoacrylate gel, a drop of which was placed on the unprepared skin. A glass sampler was then pressed on to this for 30 seconds and removed. This removed the pilosebaceous keratin and its resident bacteria. The sampler was immediately placed into a nutrient medium containing ballotini beads. Axial rotation of the sampler disperses the organisms into the medium which is plated out for qualitative and quantitative analysis. The precise details of this technique will be reported elsewhere (Holland et al., 1973). The samples for surface lipid composition and bacteria were always collected from constant sites in each patient at each visit to avoid site variation.

\section{Results}

There was considerable and significant clinical improvement at the first, second, and third months (fig. 1) and this improvement was associated with a mean serum tetracycline level of $1.98 \mu \mathrm{g} / \mathrm{ml}$ (fig. 2). Though the level slightly increased from the first to the third month, this rise was not significant.

The surface lipid composition varied with treatment. There was no constant variation of the wax ester or squalene, but the squalene levels rose significantly and the wax ester fell significantly at the end of the first month (figs. 3 and 4). Thereafter, there was no significant difference whatsoever between the control and treatment values. The most striking differences, however, were seen in the free fatty acids (fig. 5), which showed a continuous and significant reduction at the first, second, and third months, and this was associated with a concomitant significant increase in the surface lipid triglyceride (fig. 6). There was also a significant decrease in the surface lipid cholesterol (fig. 7).

Though keratin-coated hair units tended to decrease with therapy this was not significant except at the second month (fig. 8). There was, however, a significant decrease in the amount of coated material (keratin) on each hair fibre (fig. 9).

University of Leeds

K. T. HOLLAND, PH.D., Bacteriologist

R. D. ROLMES, D.SC., PH.D., Professor of Anatomy 


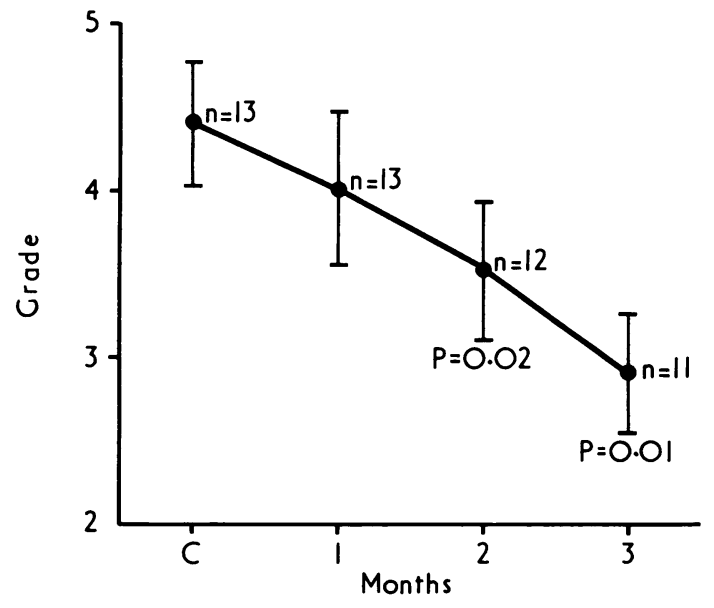

FIG. 1-Mean effect of tetracycline on clinical state $( \pm$ S.E. of mean). $n=$ No. of observations at each visit.

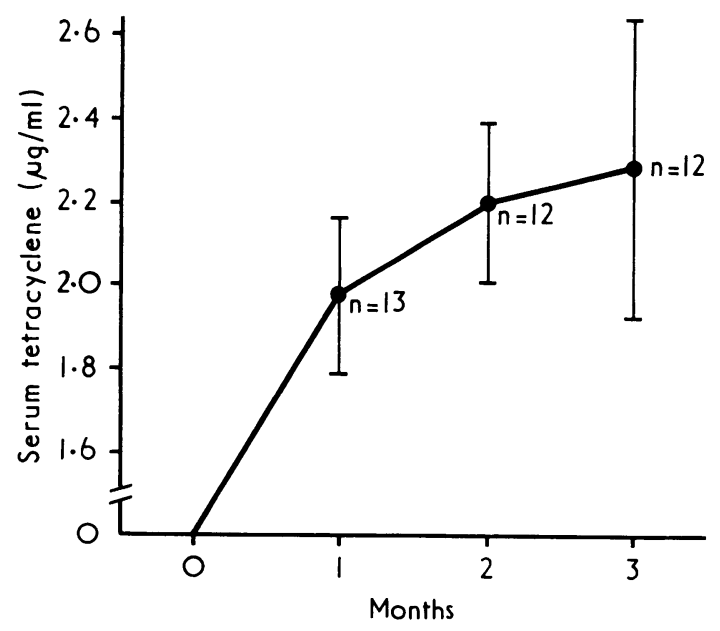

FIG. 2-Mean serum tetracycline levels ( \pm S.E. of mean).

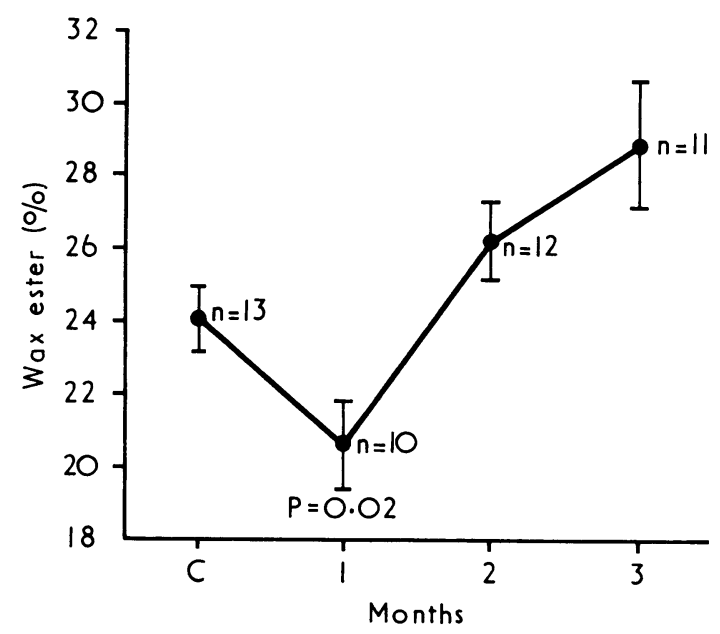

FIG. 3-Mean wax ester content of surface lipids $( \pm$ S.E. of mean).

Because of the wide variation in the number of bacteria grown and in the number of species isolated the number of bacteria (using a logarithmic scale) were converted to percentages of the peak value for each bacteria. Results at other times during the study were recorded as a percentage of this peak value. There was no significant variation in the number of

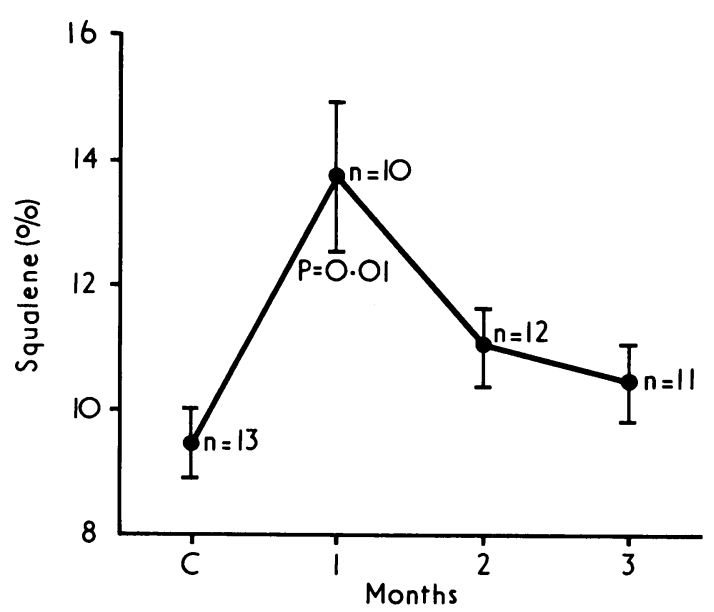

FIG. 4-Mean squalene content of surface lipids ( \pm S.E. of mean).

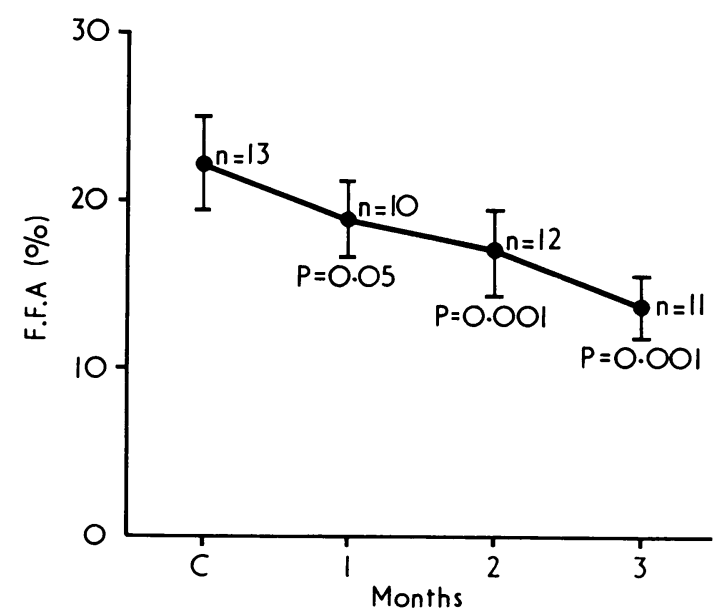

FIG. 5-Mean free fatty acid (F.F.A.) content of surface lipids ( \pm S.E. of mean).

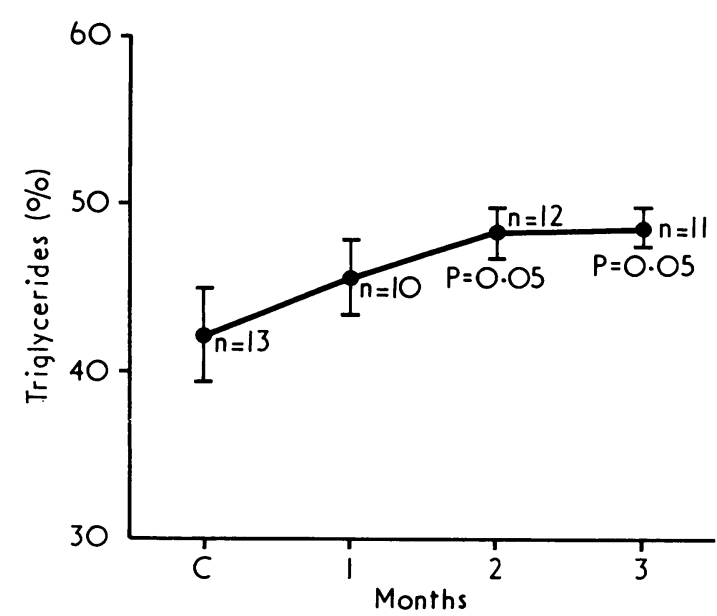

FIG. 6-Mean triglyceride content of surface lipids $( \pm$ S.E. of mean).

organisms grown (fig. 10). It would appear at first sight that the anaerobic staphylococci increase, but since they were isolated from only four of 13 subjects then this increase was not significant. We also carried out drug sensitivities and these showed rather inconsistent changes, there being no constant development of resistant strains. 


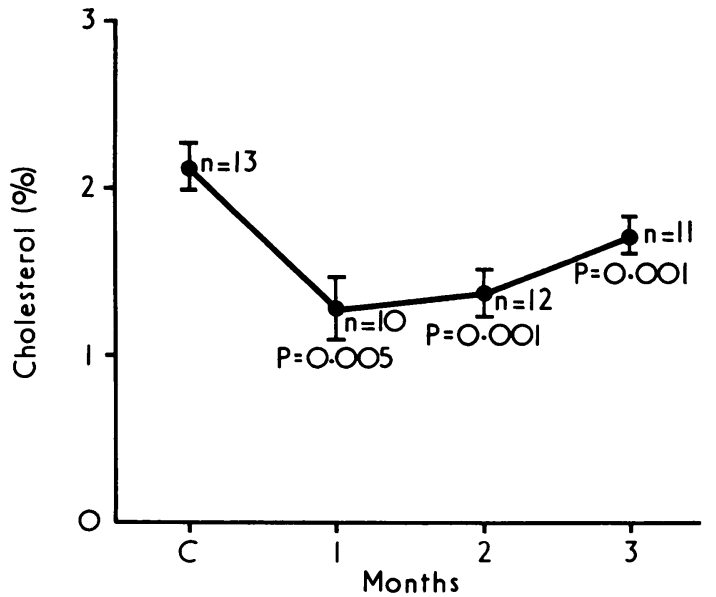

FIG. 7-Mean cholesterol content of surface lipids $( \pm$ S.E. of mean).

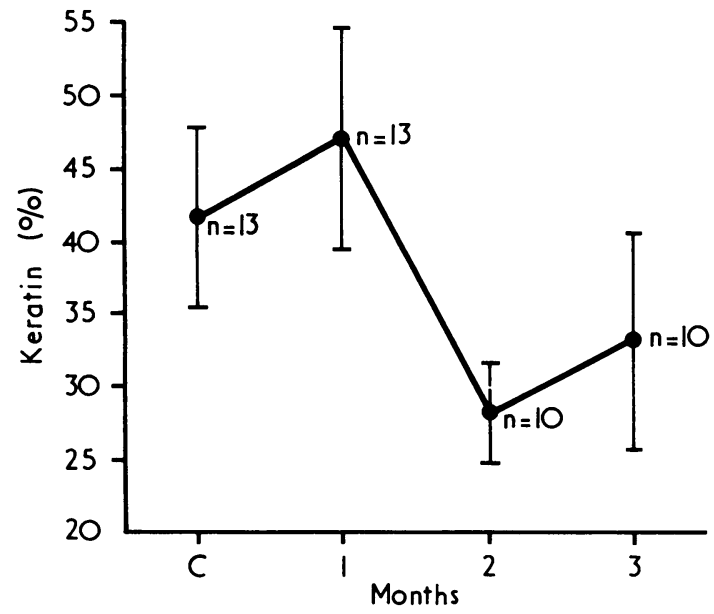

FIG. 8-Mean percentage of hairs which were coated with keratin ( \pm S.E. of mean).

\section{Discussion}

We have confirmed the clinical observation that tetracycline is beneficial in acne (Ashurst, 1968; Lane and Williamson, 1969). Our present data in which we found a mean level of tetracycline of $1.98 \mu \mathrm{g} / \mathrm{ml}$ contrast with that of a prior study (Cunliffe et al., 1972) in which we had three patients who did not respond well to tetracycline; their serum tetracycline level taken under identical conditions was always less than $0.5 \mu \mathrm{g} / \mathrm{ml}$.

Our observation of an increased squalene and decreased wax ester at the end of the first month is difficult to explain but a decreased wax ester is in keeping with the observation of Beveridge and Powell (1969). Our findings of a decrease in the fatty acids and the reciprocal increase in triglycerides confirms the findings of many other workers (Freinkel et al., 1965; Strauss and Pochi, 1966; Beveridge and Powell, 1969; Hassing, 1971). However, the decrease in the cholesterol has been reported only once previously by Gloor et al. (1972).

We have confirmed our earlier observations (Holmes et al., 1972) that successful treatment with tetracycline is associated with a decrease in the amount of keratin in the pilosebaceous duct. Possibly this decrease in keratin coating is related to the lowering of the surface lipid free fatty acids since free fatty acids are important in the formation of comedones (Kligman and Goldman-Katz, 1968). It is therefore not surprising that a reduction in the free fatty acids should be associated with a reduction in the amount of keratin in the pilosebaceous duct.

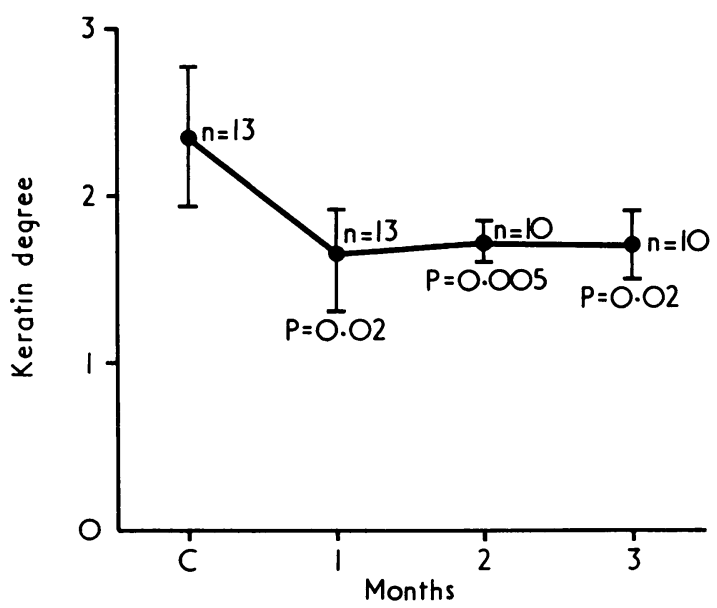

FIG. 9-Mean severity of keratin coating ( \pm S.E. of mean).

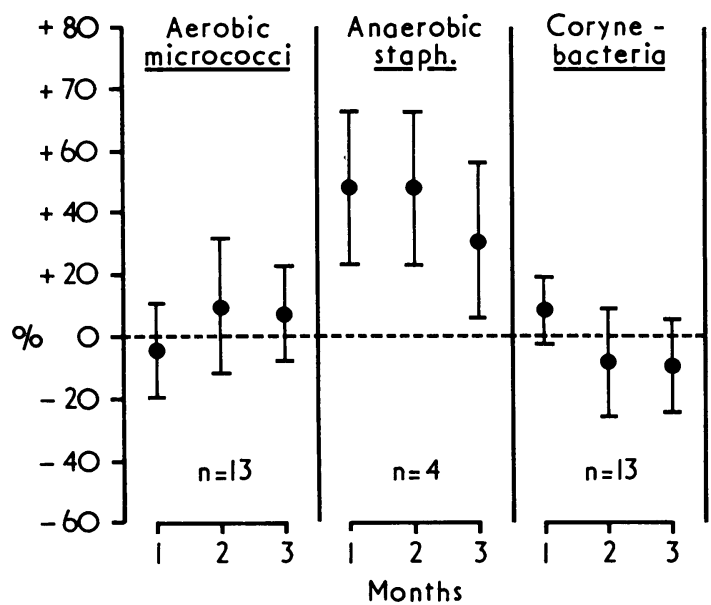

FIG. 10-Mean increase $( \pm)$ or decrease $(-)$ in bacterial flora during treatment ( \pm S.E. of mean).

This also could explain the lowered surface lipid cholesterol, since cholesterol is derived from keratinizing epidermis rather than the sebaceous gland (Cotterill et al., $1971 \mathrm{~b}$ ). Nevertheless, we were surprised that we did not find any decrease or increase whatsoever in the bacterial flora. This is in contrast to other authors (Marples and Kligman, 1971; Marples et al., 1971) who found a decrease in Corynebacterium acnes and a transient decrease with a rapid rise to original levels in staphylococci. Goltz and Kjartansson (1966) found a decrease in corynebacteria and staphylococci on a similar dose of tetracycline. However, reanalysis of their data showed this change to be insignificant.

Direct comparison of our data with other authors' observations is not possible for several reasons. Firstly, their techniques involve the collection of superficial skin organisms as well as organisms from the pilosebaceous duct. We believe that our technique specifically samples bacteria from the pilosebaceous duct. Furthermore, the doses that many previous authors have used have usually been three or four times the dose of tetracycline we used and therapy was often for about six weeks and no longer. The dose of tetracycline used in our investigation produced clinical improvement and a significant decrease in the fatty acids but no change in the bacterial flora. It is therefore suggested that at this dose the decreased fatty acid formation is due to a direct effect of the tetracycline on extracellular lipases. It is known that tetracycline can inhibit extrabacterial lipases (Hassing, 1971) and therefore it appears that tetracycline can influence triglyceride hydrolysis by inter- 
fering with extracellular lipases before killing the bacteria.

We thank the Wellcome Trust, Vick International, the Board of Governors at the Leeds General Infirmary, and the Leeds Regional Hospital Board for financial support. We also thank Mrs. L. J. A. Macpherson for technical help and the department of pharmacology for the use of the spectrofluorimeter. We also thank Mrs. L. Lane for secretarial help. Tetracycline hydrochloride reference standards were provided by Lederle Labs. Ltd. and the World Health Organization.

\section{References}

Ashurst, P. J. (1968). Practitioner, 200, 539.

Beveridges, G. W., and Powell, E. W. (1969). British fournal of Dermatology, $81,525$.

Cotterill, J. A., Cunliffe, W. J., Williamson, B., and Forster, R. A. (1971 a), British fournal of Dermatology, 85, 25.

Cotterill, J. A., Cunliffe, W. J., and Williamson, B. (1971 b). British fournal of Dermatology, 85, 40 .
Cunliffe, W. J., Williams, M., and Greenwood, N. D. (1972). Personal observations.

Freinkel, R. K., Strauss, J. S., Yiu Yip, S., and Pochi, P. E. (1965). New England Fournal of Medicine, 273, 850 .

Gloor, M., Graumann, U., Weigand, I., and Freidrich, H. (1972). Archiv für Dermatologische Forschung, 242, 309.

Goltz, R. W., and Kjartansson, S. (1966). Archives of Dermatology, 93, 92.

Hassing, G. S. (1971). Fournal of Investigative Dermatology, 56, 189 .

Holland, K. T., Roberts, C. D., Williams, M., and Cunliffe, W. J. (1973). In press.

Holmes, R. L., Williams, M., and Cunliffe, W. J. (1972). British fournal of Dermatology, 87, 327.

Kanaar, P. (1971). Dermatologica, 142, 14.

Kligman, A. M., and Goldman-Katz, A. G. (1968). Archives of Dermatology, 98, 53 .

Kohn, K. W. (1961). Analytical Chemistry, 33, 362.

Lane, P., and Williamson, D. M. (1969). British Medical fournal, 2, 76.

Marples, R. M., Downing, D., and Kligman, A. M. (1971). Fournal of Investigative Dermatology, 5, 62

Marples, R. M., and Kligman, A. M. (1971). Archives of Dermatology, 102, 148 .

Shehadeh, N. H., and Kligman, A. M. (1963). Archives of Dermatology, 88, 829. Smith, E. L., and Mortimer, P. R. (1967). British fournal of Dermatology,
79, 78 .

Strauss, J. S., and Pochi, P. E. (1965). Archives of Dermatology, 92, 443.

Strauss, J. S., and Pochi, P. E. (1966). Fournal of Investigative Dermatology, $47,577$.

\title{
Coma Associated with Vincristine Therapy
}

\author{
J. A. WHITTAKER, \\ D. H. PARRY, C. BUNCH, \\ D. J. WEATHERALL
}

British Medical fournal, 1973, 4, 335-337

\section{Summary}

Three cases of coma after vincristine therapy are described. One patient had hyponatraemia and other features of inappropriate secretion of antidiuretic hormone. The effects were temporary, and full recovery occurred in all three patients.

\section{Introduction}

Though vincristine therapy is commonly complicated by a peripheral neuropathy (Finkel, 1967) central nervous system effects have been less frequently reported. Coma is particularly uncommon (Kleinknecht et al., 1967; Loo and Zittoun, 1969; Johnson et al., 1973) and in some patients it has been associated with hyponatraemia ascribed to inappropriate secretion of antidiuretic hormone (Fine et al., 1966; Slater et al., 1969). We report here three further patients with reversible coma after vincristine therapy, one of whom was also noted to have hyponatraemia during the period of unconsciousness.

\section{Case 1}

A 65-year-old man was admitted to the University Hospital of Wales on 24 April 1973 with a one-month history of increasing shortness of breath. On examination he was pyrexial (temperature $38.5^{\circ} \mathrm{C}$ ) and a pleural rub was audible at the left base. There was mod-

\footnotetext{
Department of Haematology, Welsh National School of Medicine Cardiff CF4 4XW

J. A. WHITTAKER, M.D., M.R.C.P., Senior Lecturer

D. H. PARRY, M.B., B.S., Senior Registrar

Department of Haematology and Nuffield Unit of Medical Genetics,

University of Liverpool, Liverpool L69 3BX

C. BUNCH, M.B., CH.B., M.R.C. Research Assistant

D. J. WEATHERALL, M.D., F.R.C.P., Professor
}

erate hepatosplenomegaly but no purpura or lymphadenopathy, and a full examination of the central nervous system showed nothing abnormal. Investigations were $\mathrm{Hb} 9.3 \mathrm{~g} / 100 \mathrm{ml}$, W.B.C. $15,600 / \mathrm{mm}^{3}$ (23\% blasts, $55 \%$ atypical monocytes), and platelets $42,000 / \mathrm{mm}^{3}$. A chest $x$-ray picture showed diffuse bilateral nodular opacities and a small pleural effusion at the left base. Blood and sputum cultures were sterile. Bone marrow examination confirmed a diagnosis of acute leukaemia of undifferentiated cel type.

Treatment was started on the third hospital day with cyclophosphamide $\left(200 \mathrm{mg} / \mathrm{m}^{2}\right.$ given intravenously). Next day he was given vincrinstine intravenously $\left(1.0 \mathrm{mg} / \mathrm{m}^{2}\right.$, total dose $\left.1.75 \mathrm{mg}\right)$ and started on cytosine arabinoside $\left(280 \mathrm{mg} / \mathrm{m}^{2}\right.$ given intravenously 12-hourly for two days) and prednisone $\left(40 \mathrm{mg} / \mathrm{m}^{2}\right.$ by mouth for five days). He remained well until the 12th hospital day when he became comatose. Next day he was just rousable, but incoherent and disorientated; he remained in this state for 11 days, when consciouness fully returned. Throughout this period there was no clinical evidence of focal neurological abnormality , and cerebrospinal fluid examination showed nothing abnormal. An electro-

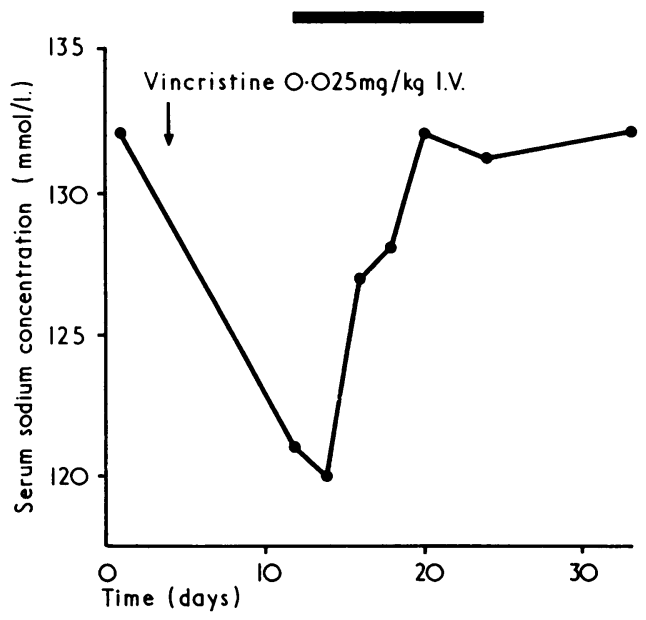

Serum sodium concentration in case 1 . Solid line represents period of unconsciousness. 